\title{
Production Planning and Planting Pattern Scheduling Information System for Horticulture
}

\author{
Tanhella Zein Vitadiar ${ }^{1,}$, Farikhin Farikhin ${ }^{1,2}$, Bayu Surarso ${ }^{1,2}$ \\ ${ }^{1}$ Master Program of Information System, Diponegoro University, Semarang - Indonesia \\ ${ }^{2}$ Faculty of Science and Mathematics, Diponegoro University, Semarang - Indonesia
}

\begin{abstract}
This paper present the production of planning and planting pattern scheduling faced by horticulture farmer using two methods. Fuzzy time series method use to predict demand on based on sales amount, while linear programming is used to assist horticulture farmers in making production planning decisions and determining the schedule of cropping patterns in accordance with demand predictions of the fuzzy time series method, variable use in this paper is size of areas, production advantage, amount of seeds and age of the plants. This research result production planning and planting patterns scheduling information system with the output is recommendations planting schedule, harvest schedule and the number of seeds will be plant.
\end{abstract}

\section{Introduction}

Production planning is one of a topic to which is of special attention for the researchers and practitioners academic industry, because it is a problem that was important in the production process, with planning production of good then can increase the company profitability [1]. Several factors that need to be considered in planning the production of is consumer demand, advantage to be achieved, a charge required during the production process, the number of resources that there was either natural resources or human resources and rescheduled, it is rescheduled planting patterns that is the determination of the schedule cropping and harvest the schedule so that it can boost the profitability of agricultural products [2].

In scheduling patterns of cropping farmers must respect all existing attributes, So as to maximize the profits of farmers, some attribute to note is, size of areas, production advantage, amount of seeds and age of the plant and production as well as the results of the life cycle of horticulture plant, in this paper study case using mushroom where mushrooms which have a life cycle as follows: mushroom life cycle averages 4 months, the process of harvesting the Mushrooms start 2 month until 4 month, harvest daily variety, mushroom harvest pattern starting from the initial harvest will always increase with each passing day until a phase peak at 2 month to 3 month and will decrease again after passing the peak phase.

For planning and scheduling patterns of cropping required a model that is able to perform calculations for planning the best among the possibilities of action that can be performed, a linear programming model is the right model because it can take decisions multi objective so different possibilities to obtain optimum resource utilization can be achieved [3].

Linear Programming is helpful in the decision for the farmers by way of the estimated number of farmer acceptance in various alternative in planning to achieve specific goals on a limited resource. These conditions encountered in agricultural commodities, such as the amount of land available, limited manpower, funding limitations and other supporting the factors such as agricultural tools are inadequate, so that Linear Programming can be used for two way i.e. minimizing costs in getting the total acceptance or total profit (minimization program) and maximize the total profit by the constraints of limited resources (maximization program) [4].

A linear Programming model is composed of the coefficients of the function of the purpose and function of the constraints which the objective function aims to describe a mathematical equation to goals are obtained while the function of mathematical equations to describe the constraints of any effect on production [5]. Then after describing the mathematical equations the next step is the calculation using the simplex method. In Linear programming, There is a sensitivity analysis. Because there is always a factor of uncertainty, sensitivity is enacting the resource parameter that is available on most small limits (Lower Limit) and limit most large (Upper Limit) it was allowed to change the parameter to a certain extents [6].

Development of cropping pattern scheduling starts with knowing the request data because the data request is the most urgent given the one key of a business is able to meet the demand of the consumer so that the consumer 
satisfaction are meet, their relationship with consumers waking, addressing the existence of the advantages and disadvantages of stock is excessive, to know the consumer demand will then do the prediction using fuzzy time series forecasting method for the future which is done based on the value of the pattern or past data of a variable or an error in the past. The concept of fuzzy time series presented based on fuzzy set theory, fuzzy logic and approximate reasoning [7].

Some literature relating with the planning production, scheduling of planting patterns in plants horticultural: tomato : Rocco dan Morabito [1], citrus : Munhoz and Morabito [8], the difference with this paper is horticulture crops study case is mushroom and this paper use 2 method there is fuzzy time series method and linear programming. Fuzzy time series prediction is very useful, if there is no farm demand to data so that the prediction results in the form of demand data can be one of the constraints variable in linear programming.

Production planning is one of the activities conducted by the company, with production planning is good then it can control the production process so that it does not produce excessive production or do not comply with the request, due to the cropping pattern of scheduling information system then expected the company can meet the amount of production effectively and efficiently so that consumer can be meet, and corporate profits can be achieved.

\section{Theoretical Framework}

\subsection{Production Planning}

The production is a set of procedures or activities conducted to create a goods and services, in any production process required a planning process. Production planning is planning about what products and how that will be produced by the company in question in a period to come. Production planning is part of operational planning within the company. In the preparation of production planning things to consider is the optimization of production so as to be able to achieve the lowest cost level for the implementation of the production process [9]. The role of planning is merely intended to coordinate the activities of the sections that directly or indirectly in producing, planning, scheduling and controlling the production of the starting stages of raw materials, process, until the resulting output so that the company really can produce goods or services effectively and efficiently.

Some of the goals of production planning, namely as a preliminary step to determine the activity of production, as a reference to more detailed planning, input of resource plans resource planning so that it can be developed to support production planning, production and labor stability against fluctuations in demand.

\subsection{Scheduling of Planting Pattern}

The cropping pattern of scheduling is a plantings on a plot of land with a set order of the layout and sequence of the plant over a given period includes the period of tillage and the period didn't planted during a certain time period [10]. Plants in one area can be set according to its kind. Monoculture cropping pattern exists, namely the growing of plants similar to the one planting acreage. There is a mixed cropping pattern, i.e., plants are grown on a single area. There is also a growing pattern of passes, that is, planting crops in turn some kinds of plants at different time on the same acreage.

In planning the production agribusiness factor to note is the cropping pattern so that scheduling can increase the profits of agriculture [11]. In the preparation of the scheduling is expected to reduce the delays in the work, and the processing time, maximizing the available working tools and labor as well as reduce the time delay.

\subsection{Information System}

Information system is a tool to present information so beneficial to the recipient for decision making on planning, controlling, and organizational management of company, information systems are used to automate the performance of routine and management activities. The field of information technology is very special because always follow the dynamic changes that develop every year there is always a new version in terms of hardware and software [12]. the basic concepts of information.

With the information system is expected to simplify and automate all the performance in the field of any kind of health, education and agriculture.

\subsection{Fuzzy Time Series}

Fuzzy time series a concept based on fuzzy set theory and its linguistic connection and application variables, fuzzy time series are used to solve the problem of forecasting which historical data are linguistic values. For example, in the matter of forecasting, historical data is not in the form of real numbers, but in the form of linguistic data. In this case, there is no conventional time series model that can be applied, but the fuzzy time series models can be applied with more precise. The main difference between the conventional and the fuzzy time series time series in the value used in forecasting, which is a fuzzy set of the real numbers over the set of hosts is specified, fuzzy set is defined as a class of numbers with vague boundaries, in this paper, fuzzy time series applied to the sale of horticulture crops in this study is mushroom, fuzzy time series used to predict demand of next month, the parameter used are Januari 2012 until April 2017.

Steps by steps with the prediction method of Fuzzy Time Series [2].

1. Partition the universe of discourse $U=[$ Drnin - D1, Dmax -[- D2] into even lengthy and equal length intervals $\mathrm{ul}, \mathrm{u} 2, \ldots$, um, historical sales of mushroom data Januari 2012 - April 2017. (1)

2. Let $\mathrm{A} 1, \mathrm{~A} 2, \ldots, \mathrm{A} \mathrm{k}$ be fuzzy sets which are linguistic values of the linguistic variable "en- rollments". Define fuzzy sets A1, A2 ..... Ak on the universe of discourse U. (2) 
3. Divide the derived fuzzy logical relation- ships into groups based on the current states of the enrollments of fuzzy logical relationships, by using the formula : $\mathrm{r}(\mathrm{MBF})^{\mathrm{w}+1}=\frac{\mathrm{MBF}_{1}+\mathrm{MBF}_{2}+\ldots+\mathrm{MBF}_{\mathrm{w}}}{\mathrm{W}}$

Dimana $\mathrm{MBF}_{1}, \mathrm{MBF}_{2}, \mathrm{MBF}_{\mathrm{w}}$ is the membership value of the sales historical data.

4. Calculate the forecasted outputs use Center of Grafity method (COG). By using the formula :

$$
\begin{array}{ll}
\mathrm{y}= & \frac{(\mathrm{A} 1 * \mathrm{c} 1+\mathrm{A} 2 * \mathrm{c} 2+\mathrm{A} 3 * \mathrm{c} 3+\ldots+\mathrm{A} 7 * \mathrm{c} 7)}{\mathrm{A} 1+\mathrm{A} 2+\mathrm{A} 3+\ldots \overline{\mathrm{A}} 7} \\
\mathrm{r}(\mathrm{NS}) * \mathrm{~A} 1+\mathrm{r}(\mathrm{NM}) * \overline{\mathrm{A}} 2+\ldots+\mathrm{r}(\mathrm{PB}) * \\
\mathrm{vi}=\mathrm{A} 7
\end{array}
$$

\subsection{Linear Programming}

Linear Programming is a general model that can be used to solving the problem of allocating limited resources optimally. The linear program includes planning activities to attain optimal results that is an outcome which reflects the achievement of a specific target is the best (according to a mathematical model) between the alternatives are possible by using a linear function, with the extant problems i.e. optimize a linear functions are limited by constraints in the form of the equation and a linear inequality [12].

In Linear Programming, there are two kinds of linear functions as follows :

a. The destination function (objective function) is a function that leads analysts to detect goal formulation problems.

b. The function of the constraints that is a direct function of the analyst to know the resources available and the demand for these resources.

Linear programming right used to potentially problematic agriculture horticulture because agricultural resources horticulture limited, a case study the research is plant of a mushroom where linear programming used to optimize advantage existing with problems such as demand was, the production not been able to meet the demand that is, the work force in need, their land less optimized, several variables need in optimize advantage is the data on demand, data production, the number of labor, data their land, data advantage production, the number of seeds and old data grow and inserted into the equation linear.

Common form of linear programming :

Maximize :

a) Objective Function: $\mathrm{Z}=\mathrm{c}_{1} \mathrm{x}_{1}+\mathrm{c}_{2} \mathrm{x}_{2}+\ldots+\mathrm{c}_{\mathrm{n}} \mathrm{x}_{\mathrm{n}}$

b) Constraint : (7)

Based on common form of linear programming, so can be concluded :

1. This is linear programming there must be function purpose (expressed with the equation a straight line function $\mathrm{z}$ or $\mathrm{f}(\mathrm{z}))$ namely benefit sales by must be agriculture.

2. Linear programming must constraints expressed with the equation a straight line, the input in function obstacles in the agricultural sector that affects sales have to less than equal to available resources on the farm.
3 . Is that all value $\mathrm{x}$ is positively or equals 0 . Or in other words, there should not be value of $\mathrm{x}$ negative . Thus hence the magnitude of the coefficients input output should not be negative.

Next phase is a method of settlement with simplex .Is a method of procedure simplex algebra that is spatially the iterative moving step by step toward the point of optimal , formulations of a method of simplex [5].

$$
\begin{aligned}
& \mathrm{x}_{1}, \mathrm{x}_{2}, \ldots, \mathrm{x}_{\mathrm{n}} \geq 0 \text { is : } \\
& \mathrm{x}_{1}
\end{aligned}
$$

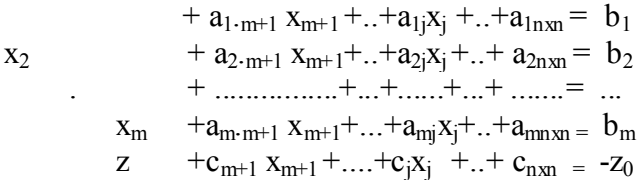

In a method of simplex function problem with inequality $((\leq)$ to be turned into equation $(=), \mathrm{z}$ is the variable the base while a1j, cj, b1 and z0 is the constant .To solution get a optimal then xn to be zero, in the form of canonical solution essentially as follows

$\mathrm{z}=\mathrm{z}_{0}, \mathrm{x}_{1}=\mathrm{b}_{1}, \mathrm{x}_{2}=\mathrm{b}_{2}, \ldots, \mathrm{x}_{\mathrm{m}}=\mathrm{b}_{\mathrm{m}}, \mathrm{x}_{\mathrm{m}+1}=\mathrm{x}_{\mathrm{m}+2}, \ldots .=\mathrm{xn}_{\mathrm{x}}=0$ In assigning value to optimal there should not be a negative value if there is to be multiplied by $(-1)$ so that the $b_{1}, b_{2}, \ldots, b_{m} \geq 0$.

\section{Result and Discussion}

The result of this research provides display system information on planning the production and scheduling planting patterns by applying a method of programming linear and fuzzy time series values is the selling data January 2012 - April 2017, so that obtained the results of optimize the production and scheduling of planting patterns. The results of data processing fuzzy time series of the results of a prediction demand for months later will be used as a function obstacles in the process of programming linear, by making formulation mathematics the determination of function the purpose and obstacles based on variables for which there are in order to obtain optimize the production and scheduling planting patterns to optimize advantage production with planted the seed mushroom in accordance with an estimated demand months later so mushroom produced according to demand that is.

Initial phase data processing started by noting the selling data, production, profit production, long planting , the amount of labor and there have in the agricultural sector mushroom the selling data January 2012 - April 2017 mixed with fuzzy time series so as to produce data demand for months later. Data demand, histori planting, the amount of labor and there have will be variable

$$
\begin{aligned}
& \mathrm{a}_{11} \mathrm{x}_{1}+\mathrm{a}_{21} \mathrm{x}_{2}+\ldots+\mathrm{a}_{\mathrm{ml}} \mathrm{x}_{\mathrm{m}} \leq \mathrm{b}_{1} \\
& \mathrm{a}_{12} \mathrm{x}_{1}+\mathrm{a}_{22} \mathrm{x}_{2}+\ldots+\mathrm{a}_{\mathrm{m} 2} \mathrm{x}_{\mathrm{m}} \leq \mathrm{b}_{2}
\end{aligned}
$$

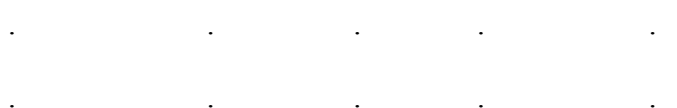

$$
\begin{aligned}
& \mathrm{a}_{1 \mathrm{~m}} \mathrm{x}_{1}+\mathrm{a}_{2} \mathrm{x}_{2}+\ldots+\mathrm{a}_{\mathrm{nm}} \mathrm{x}_{\mathrm{n}} \leq \mathrm{b}_{\mathrm{m}} \\
& \mathrm{x}_{1}, \mathrm{x}_{2}, \ldots, \mathrm{x}_{\mathrm{n}} \geq 0
\end{aligned}
$$

function obstacles data on advantage production will to 
be functions of the purpose of which will formulated in the form of mathematics by using programming linear, of the results of data processing will get some of the scenarios with the lapse of time planting mushroom different, the lapse of time planting start of an interval planting one month to hose planting 4 months to produce sum advantage different also from here function of incorporation fuzzy time series and linear programming namely optimize advantage farmers a mushroom with planting seeds mushroom in accordance with an estimated demand months later so can produce mushroom in accordance with consumer demand.

The planning process the producing and scheduling of planting patterns commenced by determining prediction demand months later using data historical sales a few years back, the data used was the selling data from year January 2012 - April 2017, the process prediction demand by using the method fuzzy time series.

Steps in fuzzy time series is

1. Partition the universe of discourse $U=[$ Drnin - D1,

Dmax -[- D2] into even lengthy and equal length intervals ul, u2, ..., um (1)

Based on data of year January 2012 - April 2017, obtained universe of discourse as follows:

$D_{\text {min }}=133$ and $D_{\max }=598$, Divided long intervals as many as 7 so obtained $\mathrm{u} 1-\mathrm{u} 7$ such as table 1 .
Table 1. Number of interval.

\begin{tabular}{|l|r|r|r|}
\hline u1 & 133 & 199.4286 & 1 \\
\hline u2 & 199.4285714 & 265.8571 & 3 \\
\hline u3 & 265.8571429 & 332.2857 & 9 \\
\hline u4 & 332.2857143 & 398.7143 & 9 \\
\hline u5 & 398.7142857 & 465.1429 & 20 \\
\hline u6 & 465.1428571 & 531.5714 & 8 \\
\hline u7 & 531.5714286 & 598 & 12 \\
\hline
\end{tabular}

2. Defines the set of fuzzy in of $U$ with determine the value of $\mathrm{nb}$ (negative big), $\mathrm{nm}$ (negative medium), ns (negative small), z (zero), ps (positive small), pm (positive medium) and pb (positive big) a curve to describe variation from the sale, as in a picture 1 .

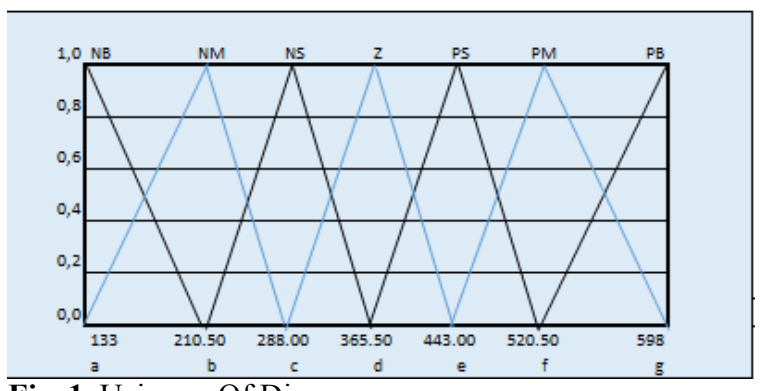

Fig. 1. Universe Of Discourse

Table 2. Fuzzification process

\begin{tabular}{|l|l|l|c|c|c|c|c|c|c|}
\hline $\begin{array}{c}\text { Universe of } \\
\text { Discourse U }\end{array}$ & \multicolumn{3}{|c|}{ Fuzzy Set } & \multicolumn{3}{c|}{ Fuzzification } & \multicolumn{2}{c|}{$\begin{array}{c}\text { Calculation } \\
\text { Fuzzy w=1 }\end{array}$} & \multicolumn{2}{c|}{$\begin{array}{c}\text { Defuzzificatio } \\
\text { n }\end{array}$} \\
\hline Month & Year & $\begin{array}{c}\text { Actual } \\
\text { Value }\end{array}$ & NB & NM & NS & Z & PS & PM & PB \\
\hline JAN & 2017 & 485 & 0.00 & 0.00 & 0.00 & 0.00 & 0.458 & 0.542 & 0.00 \\
\hline FEB & 2017 & 585 & 1.007 & 0.00 & 0.00 & 0.00 & 0.00 & 0.168 & 0.832 \\
\hline MARCH & 2017 & 417 & 0.614 & 0.00 & 0.00 & 0.335 & 0.665 & 0.00 & 0.00 \\
\hline APRIL & 2017 & 312 & 1.009 & 0.00 & 0.69 & 0.31 & 0.00 & 0.00 & 0.00 \\
\hline
\end{tabular}

Table 3. Table the results of a prediction fuzzy

\begin{tabular}{|l|l|l|l|l|l|l|l|l|l|}
\hline \multicolumn{2}{|c|}{$\begin{array}{c}\text { Universe of } \\
\text { Discourse U }\end{array}$} & \multicolumn{2}{c|}{ Fuzzy Set } & \multicolumn{2}{c|}{ Fuzzification } & Calculation Fuzzy w=1 & \multicolumn{2}{c|}{ Defuzzification } \\
\hline Month & Year & $\begin{array}{c}\text { Actual } \\
\text { Value }\end{array}$ & Y & v & $\begin{array}{c}\text { Prediction } \\
\text { value / Fi }\end{array}$ & Error & MAD & \multicolumn{2}{c|}{$\begin{array}{c}\text { MSE } \\
\text { MAPE } \\
\%\end{array}$} \\
\hline JAN & 2017 & 485 & 1.01 & 386.038 & 387.048 & 97.952 & 97.952 & 9594.594 & 4.951 \\
\hline FEB & 2017 & 585 & 1.007 & 485.005 & 486.012 & 98.988 & 9798.624 & 9798.624 & 5.91 \\
\hline MARCH & 2017 & 417 & 0.614 & 584.98 & 585.594 & -168.594 & 28423.937 & 28423.937 & 2.437 \\
\hline APRIL & 2017 & 312 & 1.009 & 417.038 & 418.047 & -106.047 & 11245.966 & 11245.966 & 2.942 \\
\hline
\end{tabular}

3. Fuzzification historical data with the $\mathrm{w}=1$, in table 2 explained the process fuzzification the final period. Namely january 2012 - april 2017. (3)

4. Defuzzification

In table 3 explained the result of a prediction in the final period to be used as variable demand at calculation linear programming and value mape.(4)
After obtained the results of predictive value demand may as many as 418 , so predictive value is used as variable consumer demand in function obstacles in calculation linear programming. Besides variable consumer demand that to be functions of obstacles is variable amount of sales, there have, working hours and 
the amount of labor (the coefficients) and variable advantage production to be functions of the purpose.

Besides the determination of function the purpose and obstacles is scenario optimize consisting of scenario one, two and three where scenario one distance planting mushrooms in one batch have hose planting one month, scenario two have hose planting two months and scenario of 3 have hose planting 3 months and scenario 4 have hose planting four months.

Calculation resolved with the methods simplex who has formulated in the form of mathematical linear model programming, the data is required for the planning the producting and scheduling of planting patterns is presented in Table 4.

Table 4. Data for a period

\begin{tabular}{|l|l|l|l|l|l|}
\hline & $\begin{array}{l}\text { Amount of } \\
\text { Sales Mush- } \\
\text { rooms (kg) }\end{array}$ & $\begin{array}{l}\text { Profit } \\
\text { (Rp) }\end{array}$ & $\begin{array}{l}\text { Seed } \\
\text { (Batch) }\end{array}$ & $\begin{array}{l}\text { Coeffi } \\
\text { cient }\end{array}$ & $\begin{array}{l}\text { De- } \\
\text { mand } \\
\text { (kg) }\end{array}$ \\
\hline X1 & 485 & 2907000 & 970 & 0.192 & 387 \\
\hline X2 & 585 & 3527000 & 1170 & 0.16 & 486 \\
\hline X3 & 417 & 2485400 & 834 & 0.222 & 586 \\
\hline X4 & 312 & 1834400 & 624 & 0.294 & 418 \\
\hline
\end{tabular}

The next step is to formulating into mathematical form linear programming.

1. Formulation programming of linear programming scenario 1

Objective Fuction

$Z=2907000 X 1+3527000 X 2+2485000 X 3+1834000 X 4$

(profit) (6)

Constraints (7)

$0.19 \mathrm{X} 1+0.16 \mathrm{X} 2+0.22 \mathrm{X} 3+0.29 \mathrm{X} 4<=288$ (koefisien)

$970 \mathrm{X} 1+1170 \mathrm{X} 2+834 \mathrm{X} 3+624 \mathrm{X} 4<=5000$ (bibit)

$485 \times 1<=387$

$1070 \times 2<=486$

$1487 \times 3<=586$

$1314 \mathrm{X} 4<=418$

2. Formulation programming of linear programming scenario 2

Objective Fuction

$Z=2907000 X 1+3527000 X 2+2485000 X 3+1834000 X 4$ (profit) (6)

Constraints (7)

$0.19 \mathrm{X} 1+0.16 \mathrm{X} 2+0.22 \mathrm{X} 3+0.29 \mathrm{X} 4<=288$

(coefficient)

$970 \mathrm{X} 1+1170 \mathrm{X} 2+834 \mathrm{X} 3+624 \mathrm{X} 4<=5000$ (bibit)

$485 \times 1<=387$

$1070 \times 2<=486$

$1002 \times 3<=586$

$729 \times 4<=418$

3. Formulation programming of linear programming scenario 3

Objective Fuction

$\mathrm{Z}=2907000 \mathrm{X} 1+3527000 \mathrm{X} 2+2485000 \mathrm{X} 3+1834000 \mathrm{X} 4$

(profit) (6)

Constraints (7)

$0.19 \mathrm{X} 1+0.16 \mathrm{X} 2+0.22 \mathrm{X} 3+0.29 \mathrm{X} 4<=288$

(coefficient)

$970 \mathrm{X} 1+1170 \mathrm{X} 2+834 \mathrm{X} 3+624 \mathrm{X} 4<=5000$ (bibit)

$485 \times 1<=387$
$585 \times 2<=486$

$417 \mathrm{X} 3<=586$

$312 \mathrm{X} 4<=418$

4. Formulation programming of linear programming scenario 4

Objective Fuction

$Z=2907000 X 1+3527000 X 2+2485000 X 3+1834000 X 4$

(profit) (6)

Constraints (7)

$0.19 \mathrm{X} 1+0.16 \mathrm{X} 2+0.22 \mathrm{X} 3<=288$ (coefficient)

$970 \times 1+1170 \times 2+834 \times 3<=5000$ (bibit)

$485 \times 1<=387$

$585 \times 2<=486$

$417 \mathrm{X} 3<=586$

From scratch linear programming completed by method simplex in the system information planning production and scheduling planting patterns obtained a result of each scenario shown in table 5 .

Table 5. Comparison every scenario (SC)

\begin{tabular}{|c|c|c|c|c|c|c|}
\hline \multirow{2}{*}{$\mathrm{SC}$} & \multirow{2}{*}{$\begin{array}{l}\text { Interval } \\
\text { Planting } \\
\text { (mount) }\end{array}$} & \multicolumn{4}{|c|}{$\begin{array}{c}\text { Number of seeds grown } \\
\text { (mount) }\end{array}$} & \multirow{2}{*}{$\begin{array}{c}\text { Profit } \\
\text { (Rp) }\end{array}$} \\
\hline & & $1 \mathrm{st}$ & 2nd & $3 \mathrm{rd}$ & 4th & \\
\hline 1 & 1 & 774 & 531 & 164 & 115 & 5.327 .200 \\
\hline 2 & 2 & 774 & 531 & 487 & 357 & 6.426 .900 \\
\hline 3 & 3 & 774 & 972 & 1172 & 836 & 11.200 .000 \\
\hline 4 & 4 & 774 & 972 & 1172 & - & 8.742 .400 \\
\hline
\end{tabular}

Calculation scenario 1, 2, 3, and 4 showed optimal results found in scenario 3 with a hose planting three months. In an analysis of solution optimal the number of planting in scenario 3 in proportion to the number of requests that is while in scenario 1 and 2 scenario the number of planting excess and also on scenario 4 the number of planting in 1 year only 3 cropping.

Results obtained in scenario 3 as much $\mathrm{Rp}$ 11.200.000,00 with the number of mushroom that must be produced in a period as many as x1: 775, x2: 972, x3: 1172 and $x 4$ : 836 , recommendations the number of mushroom should be planted based on formulation programming linear and calculation with the methods simplex namely the results of multiplied by the number of seeds grown, planting patterns to be demonstrated in table 6.

Table 6. Planting patterns distance planting three months

\begin{tabular}{|l|c|c|c|c|c|c|c|c|c|c|c|c|}
\hline & \multicolumn{10}{|c|}{ Month } \\
\hline X1 & J & F & M & A & M & J & J & A & S & O & N & D \\
\hline X2 & T:775 & P & P & P & & & & & & & & \\
\hline X3 & & & & & T:1173 & P & P & P & & & & \\
\hline X4 & & & & & & & & & T:837 & P & P & P \\
\hline
\end{tabular}




\section{Conclusions}

Based on the research done and discussion information system planning the production and scheduling planting patterns this can provide recommendations planting patterns and the number of mushroom should be planted in a period by farmers mushroom, the life cycle mushrooms in a period is four months, the number of planting adapted to the number of requests is there who had previously been predicted by using fuzzy time series, the results showed of four scenario hose planting obtained a value on first scenario distance planting a month $\mathrm{Rp}$ 5.327.266,00, on second scenario, The distance planting two months Rp 6.426.950,00, value third scenario , the distance planting three months worth $\mathrm{Rp} 11.200 .000,00$, and the distance planting four months worth $\operatorname{Rp~8.742.400,00~based~on~the~results~of~}$ scenario one, two, three and four obtained value optimal in scenario to three $\mathrm{Rp} 11.200 .000,00$ with seeds planting mushroom do not all planted in early, but broken down with seeds planting next given a distance of three months as many as planting the first month 775 , second its 972 , third 1172 , and fourth 836 .

\section{References}

1. S. A. Raza, F. C. Abdullakutty, and S. Rathinam, Applied Mathematical Modelling 40, 8446 -8463 (2016).

2. N. M. C. Garcia, A. G. B. Lozano, and Y. A. R. Solis, Computers and Electronics in Agriculture 107, $20-28$ (2015).

3. B. B. Pal, M. Kumar, and S. Sen, Second International conference on Computing, Communication and Networking Technologies (2010).

4. G. Dantzig, Linier Programming and extensions. The Rand Corporation (1963).

5. A. G. Martín, C. Pozo, and G. G. Gosalbez, Land Use Policy 48, 515 - 524 (2015).

6. C. D. Rocco, and R. Morabito, Computers and Electronics in Agriculture 127, 763 - 774 (2016).

7. Q. Song, and B., S. Chissom, In Fuzzy Sets and System 54, 1 - 9 (1993).

8. J.R. Munhoz, R. Morabito, Comput. Electron. Agric 107, 45-57. (2014).

9. J. Heizer, B. Render, Operation Management Tenth edition. US : Pearson (2005).

10. N. A. Campbell, Biology Tenth edition. US : Pearson (2002).

11. R. A. R. Junqueira, and R. Morabito, Computers and Electronics in Agriculture 84, 100 - 110 (2012).

12. V. Democ, Z. Vyhnalikova, P. Alac, Procedia Economics and Finance 34, 477 - 484 (2015). 